\title{
Happier with less? Members of European environmental grassroots initiatives reconcile lower carbon footprints with higher life satisfaction and income increases
}

\author{
Gibran Vita ${ }^{\mathrm{a}, 1,2,3}$, Diana Ivanova ${ }^{\mathrm{a},{ }^{*}, 1,4}$, Adina Dumitru ${ }^{5}$, Ricardo García-Mira ${ }^{5}$, Giuseppe Carrus ${ }^{6}$, \\ Konstantin Stadler ${ }^{1}$, Karen Krause ${ }^{7}$, Richard Wood ${ }^{1}$ and Edgar G. Hertwich ${ }^{1,8}$ \\ ${ }^{1}$ Industrial Ecology Programme, Department of Energy and Process Engineering, Norwegian University of \\ Science and Technology, Trondheim, Norway. \\ ${ }^{2}$ Faculty of Management, Science and Technology, Open University, The Netherlands \\ ${ }^{3}$ Center for Environmental Systems Research, University of Kassel, Germany \\ ${ }^{4}$ School of Earth and Environment, University of Leeds, Leeds, UK \\ ${ }^{5}$ People-Environment Research Group, Faculty of Educational Sciences, University of A Coruña, Spain \\ ${ }^{6}$ Department of Education, Roma Tre University, Rome, Italy \\ ${ }^{7}$ Otto von Guericke University Magdeburg (OVGU), Magdeburg, Germany \\ ${ }^{8}$ Center for Industrial Ecology, School of Forestry and Environmental Studies, Yale University, New \\ Haven, CT, USA. \\ a These authors contributed equally to this work \\ * Correspondence: d.ivanova@leeds.ac.uk, diana.nbd@gmail.com
}

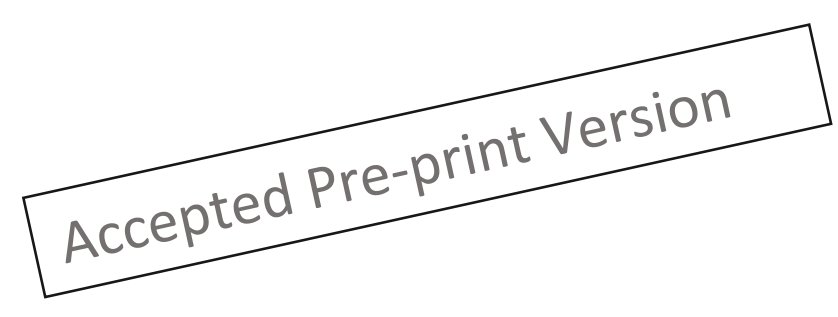

Citation:

Vita*, G., Ivanova*, D., Dumitru, A., García-Mira, R., Carrus, G., Stadler, K., Wood, R., Hertwich, E. G. (2020). Happier with less? Members of European environmental grassroots initiatives reconcile lower carbon footprints with higher life satisfaction and income increases. Energy Research and Social Science, 60. *Shared first-authorship https://doi.org/10.1016/j.erss.2019.101329 


\section{Abstract}

Scientists and policymakers recognize the need to address consumption and lifestyles in order to reconcile environmental and development agendas. Sustainability-oriented grassroots initiatives emerge bottom-up to create opportunities for sustainable lifestyles; yet no prior assessment has ascertained the efficacy of their members to reduce carbon footprints (CF) and enhance well-being. We compare the $\mathrm{CF}$ of non-members and members of grassroots initiatives in the domains of food, clothing, housing and transport. We further compare the groups by testing the influence of socio-economic variables that are typically associated with both footprint and well-being. Here we show that grassroots initiative members have $16 \%$ lower total carbon footprint, and $43 \%$ and $86 \%$ lower carbon footprints for food and clothing respectively, compared to their "non-member" regional socio-demographic counterparts. We find a higher adoption of some energy-saving behaviors for initiative members such as greater active travel distance and lower indoor temperatures in the winter, yet no significant differences in the CF of housing and transport. Interestingly, increases in income are not associated with increases in the total CF of members, while the influence of income is confirmed for the CF of the total sample. Instead, factors such as age, household size, and gender better explain the variation in the domain-specific CFs of initiative members. Finally, members show higher life satisfaction compared to non-members and are $11-13 \%$ more likely to evaluate their life positively. Our results suggest that initiative members uncover lifestyle features that not only enable lower emissions, but also reconcile emissions with income and well-being.

\section{Author contributions}

GV and DI contributed equally to the analysis and design of the letter. RGM, AD, EH, and GC contributed to the planning of the research project. DI, GV, RGM, AD, GC, KK and KS contributed to the pilot and final survey design. RGM, AD, KK and GC participated in the sampling, contacted initiatives, distributed, collected and processed the survey data. $\mathrm{EH}, \mathrm{RW}$, KS, DI and GV contributed to the carbon calculator model. All authors contributed to the results discussion and manuscript editing. DI and GV share first authorship given their contributions as indicated above.

\section{Competing interests}

The authors declare no competing financial interests.

\section{Acknowledgements}

This work is an output of the GLAMURS project financed by the European Union's seventh framework program (contract 613420). We thank all GLAMURS partners who contributed to the survey - in its design, distribution, collection of results and analysis. The list includes but is not necessarily limited to, Alberto Díaz-Ayude and Helena Martínez Cabrera from UDC, Ines Omann, Mirijam Mock, Paul Lauer and Ines Thronicker from UFZ, Fridanna Maricchiolo, Angelo Panno, Ambra Brizi and Eugenio de Gregorio from the Roma Tre University, Irina Macsinga and Vlad Pandur from UVT, Maxie Schulte, Ellen Matthies and Anke Blöbaum from OvGU. The authors thank Angela McLean for writing assistance and Xiangping Hu for his statistical guidance. We would also like to thank Karen O'Brien for providing feedback on an early draft. 


\section{Introduction}

With the United Nation's $12^{\text {th }}$ Sustainable Development Goal (SDG) of Responsible Production and Consumption, the global community aims to reconcile the goals of economic development (SDG8) and environmental protection (SDG12-15) ${ }^{1}$. Thus far, the global rise in income and consumption has driven environmental impact with a strength that can hardly be offset by technological progress ${ }^{2,3}$. Furthermore, while technical progress may increase resource efficiency, it can also lead to undesirable rebound effects -i.e., increases in total consumption which diminish the mitigation potential from efficiency gains ${ }^{4}$.

The notion of "green growth" assumes that economic growth could be decoupled from greenhouse gas (GHG) emissions via sustainable resource management, strong abatement and efficient resource use ${ }^{5,6}$. The decoupling pursuit is endorsed by simulation-based research and influential policy agendas ${ }^{5,6}$. Nevertheless, empirical evidence over the past decades shows that no nation has achieved absolute decoupling and that most reported evidence has either overlooked problemshifting to other resources or countries ${ }^{7,8}$.

As a response to realizing the limits of "green growth" via decoupling, 9 , alternative models such as "living well" (Sumac Kawsay) in the Global South and "sustainable de-growth" in the Global North, have gained traction across academic, policy and civil spheres ${ }^{11-13}$. Their core assumption is that "a good life can be decoupled from environmental damage" 11,12,14. Their common proposal is to satisfy fundamental human needs directly by endorsing goods and practices that effectively reconcile higher well-being with reduced impact ${ }^{14-16}$. Sustainability-focused grassroots initiatives are suggested to have a role towards this end. Nevertheless, their potential to enable lifestyles of lower impact and higher well-being has not been fully understood ${ }^{17-19}$.

\section{The potential and constraints of lifestyle changes}

Given that household consumption drives about $65 \%$ of global GHG emissions ${ }^{20}$, there is a major interest in embedding demand-side solutions into climate change mitigation strategies ${ }^{4,21}$. Examples of consumer-oriented policies include creating economic ${ }^{4}$ and non-economic ${ }^{22,23}$ incentives to adopt low-impact behaviors, social norm-based interventions which normalize sustainable practices ${ }^{24}$, behavioral 'nudges' that make low-impact choices the default option ${ }^{10,21}$, and locking-in desirable practices through adequate infrastructures. However, consumer-side policy interventions have their own pitfalls. They can be costly and short-lived if they do not hit the deepest leverage points of social transformation ${ }^{25-27}$ : the underpinning values, goals, intrinsic motivations $^{22}$ and world views that govern society ${ }^{24,26}$.

Even individuals with pro-environmental orientations may be ineffective at reducing their CF due to the dominant influence of socio-economic factors on consumption levels ${ }^{28-30}$. Particularly, they may focus on behaviors that are easy to adopt, but have relatively small impact ${ }^{28,31}$ e.g., recycling. Typically, the available voluntary lifestyle changes are often limited to consumption of less harmful goods or "green consumption"10,32, and constrained by institutional, infrastructural and behavioral lock-ins ${ }^{30,33,34}$. Furthermore, only a massive adoption of lifestyle changes would represent a serious contribution towards keeping within $1.5^{\circ} \mathrm{C}$ trajectories ${ }^{35,36}$. For these and other reasons, pro- 
environmental knowledge $\mathrm{k}^{31,37}$, attitudes ${ }^{28,37}$ and even behaviors ${ }^{38}$ are no guarantee of substantial impact reductions ${ }^{28,31,38}$.

\section{Sustainability-oriented grassroots initiatives}

Sustainability-oriented grassroots initiatives are bottom-up networks of individuals and organizations with an overarching agenda of social and environmental well-being 9,10 . They are fueled by volunteers and function through social learning by sharing new practices and skills among members ${ }^{37}$. The sustainability causes sought by grassroots initiatives vary widely. Initiatives can be specialized, such as food and energy cooperatives, or comprehensive, such as the Transition Town Movements ${ }^{39}$ and eco-villages ${ }^{37}$. Some initiatives focus on satisfying needs beyond market offer by taking a role of "prosumers" and producing the goods they wish to consume $^{10,37}$. Other try to modify or extract themselves from current structural hurdles ${ }^{37}$. Overall, all initiatives attempt to create alternative social practices that best align with the values and envisioned lifestyles pursued by their members ${ }^{10,40,41}$.

Grassroots initiatives can influence society on multiple levels ${ }^{37}$. At the individual level, initiatives offer knowledge, role-models and social support to adopt sustainable lifestyles while satisfying needs ${ }^{10,42}$. At the group or network level, they enrich social capital by spurring social learning ${ }^{17,37}$, mobilizing for environmental citizenship ${ }^{32}$ and incubating innovation niches ${ }^{17,34}$. At the societal level, they can influence the underlying rules and norms, creating a supportive normative context for sustainable policies ${ }^{24,26}$. When successful, grassroots initiatives operate at the deepest leverage points $^{25}$, challenge current paradigms ${ }^{26}$, and empower individual and collective capacity towards sustainability transformation ${ }^{26,43}$.

Indeed, previous research indicates that grassroots initiatives play a role in sustainability transitions ${ }^{10,17,26,32,37,39}$ by providing counter-narratives of economic development with an embedded perspective of intrinsic motivations, values underpinning social relations and pathways to sustainable lifestyles ${ }^{44,45}$.

In this sense, grassroots initiatives can foster voluntary simplicity. Contrary to the notion that consumption determines well-being 9,16 , proponents of lifestyles driven by voluntary simplicity argue for a "double dividend": simultaneously reducing consumption while enhancing wellbeing $9,16,40$. Previous studies suggest that participation in grassroots initiatives could be linked to increased awareness and pro-environmental behaviors, while supporting individuals in the pursuit of well-being ${ }^{46-48}$ and quality of social life ${ }^{40,41,44}$.

\section{Previous research on members of grassroots initiatives}

Members of environmental organizations have been reported to perform pro-environmental behaviors more frequently than the general public ${ }^{49,50}$. As a variable, group membership captures the relevant social context in which individuals develop or re-inforce environmental attitudes, habits and lifestyles ${ }^{50}$. However, few studies assess the environmental impact of members and they do so through assessing behavior ${ }^{28,29,41}$ or direct energy use ${ }^{49}$, overlooking that (pro-environmental) behaviors are not always the ones associated with the highest environmental impacts i.e., the socalled behavior-impact gap ${ }^{28,38}$. Furthermore, previous research has been limited to study active 
and passive members of broadly defined environmental organizations, ranging from multi-national non-governmental organizations to charities ${ }^{29,31,41,50}$.

Early research suggested a positive associating between activism and well-being ${ }^{47}$, and between lower ecological footprint and higher well-being i.e. voluntary simplicity ${ }^{40,51,52}$. However, there is a lack of comprehensive and quantitative assessments on the environmental impact and well-being of members of grassroots initiatives $17,39,47,53$, with the vast majority of related studies either undertaking a theoretical approach ${ }^{17,19,43,53,54}$ or focusing solely on intentional communities ${ }^{48,53,55}$.

A recent systematic review compared the environmental impact of regular citizens to inhabitants of intentional communities, such as ecovillages and co-housing communities established with the explicit goal of reducing environmental impact ${ }^{53}$. The review found an average of $35 \%$ lower emissions for members ${ }^{53}$-while none of the covered studies controlled for socio-economic differences ${ }^{53}$. Further, the review included a wide range of geographies and combined carbon metrics, with only two studies based on $\mathrm{CO}_{2}$-equivalents but not through a lifecycle approach ${ }^{53}$. Another study on members that voluntarily limit their carbon allowance coincidentally also found a $35 \%$ reduction with respect to UK average, but the participants calculated their own footprint using diverse carbon accounting methods ${ }^{54}$. Grinde et al reported the potential of intentional communities to reconcile higher mental well-being with lower income, despite higher education ${ }^{55}$. Mulder et al found higher well-being and lower material throughput for members of intentional communities, although their impact assessment was limited to transport ${ }^{48}$.

The GLAMURS (Green Lifestyles, Alternative Models and Upscaling Regional Sustainability) ${ }^{1}$ project applied an interdisciplinary approach to research the main obstacles and prospects for sustainable lifestyles in Europe at national ${ }^{20}$, regional $^{2}$ and individual levels ${ }^{30}$-including participatory modelling with stakeholders to quantify the potential of lifestyle changes ${ }^{35}$. Empirically, the project conducted action research with grassroots initiatives ${ }^{56}$ and applied a comprehensive survey to compare the lifestyles of non-members with the lifestyles of members of local sustainability-oriented grassroots initiatives ${ }^{56}$. In this study, we used the GLAMURS survey to test for evidence of voluntary simplicity by exploring the carbon footprint and well-being of members of grassroots initiatives. We advance from behavioral proxies and direct energy use by estimating the carbon footprint embodied in the most impactful consumption domains ${ }^{2,20}$, covering both direct energy use and indirect impacts through purchase of goods and services. Noteworthy, we do not test for causality between joining an initiative and environmental or well-being outcomes. Rather, we test for observable carbon and life satisfaction differences between members and non-members, while controlling for relevant socio-demographic factors.

\section{Data}

Here we analyzed the CF of 141 moderately to highly engaged adult members of 12 sustainabilityfocused grassroots initiatives located in Italy, Germany, Romania and Spain. The chosen regions lie in close proximity to the research teams of the GLAMURS project and represent a diversity of economic, cultural and geographical contexts. As a sample, they provide an opportunity to investigate sustainability-oriented grassroots initiatives spanning different issues, ambitions and

\footnotetext{
${ }^{1}$ More about the EU-FP7 funded GLAMURS project and its case studies can be found at http://glamurs.eu/
} 
lifestyle domains across Europe. The studied initiatives include food and clothing cooperatives, eco-villages and the Transition Town Movement. We evaluated the individual CF and life satisfaction of initiative members and compared them to non-members sampled from the same geographical regions $(\mathrm{N}=1,476)$.

In this study, the concept of "sustainability-oriented grassroots initiatives" refers to groups or networks of individuals and organizations engaged in any of the SDGs ${ }^{9,10}$ with an overarching agenda of social and environmental well-being. In this study, all the sampled initiatives share a focus on the SDG12 of Responsible consumption and production (Table 1). The set of initiatives were selected in order to include both comprehensive lifestyle change initiatives (e.g., eco-villages, Transition Town) as well as issue-based initiatives (e.g., food cooperatives, sustainable consumption). Some limitations with regards to initiative representativeness and initiative focus are discussed in the section on "Limitations and future work".

We based our analysis on a self-reported survey which captured demographic variables, socioeconomic status, expenditure, environmentally relevant behaviors, living standards, and life satisfaction. We calculated the embodied CF of food, clothing, housing and transport from expenditure, travel and dietary surveys, and housing conditions. We controlled for socio-economic and demographic variables to compare groups through a multiple regression analysis. Finally, we used evaluations of life satisfaction to assess well-being across groups and in relation to CF. The methods and Supplementary Information (SI) contain further detail about the samples, survey items and CF calculations (SI1-3).

\section{Samples}

The sample of non-members $(\mathrm{N}=1,476)$ were adult inhabitants from the regions of Galicia (Spain), Banat-Timis (Romania), Lazio (Italy) and Saxony-Anhalt (Germany). The initiative sample $(\mathrm{N}=141)$ included 12 grassroots initiatives with varying sustainability focus. The sample of initiative members in Galicia included 59 members from the food cooperative Zocamiñoca $(\mathrm{n}=40)$, and Amarante Setem $(\mathrm{n}=13)$, and Equus Zebra $(\mathrm{n}=6)$, which focus on food and clothing consumption. The sample from Banat-Timis included 20 members from Aurora and Amonia Brassovia eco-villages. The sample for Lazio included a network of agricultural and food cooperatives with focus on food consumption and regional production of organic food $(\mathrm{n}=27)$. The initiative sample from Saxony-Anhalt comprise 35 members from Transition Town Halle $(\mathrm{n}=21)$ and Lebensmittel retten Magdeburg ( $\mathrm{n}=14$ ), where the former is of an extensive scope while the latter focuses on sustainable food consumption and food waste prevention. See SI1 for details about initiative scope and activities.

Table 1. Overview of the sustainability grassroots initiatives in our study
\begin{tabular}{l|l|l|} 
Initiatives & Domain of action & Activities \\
\hline $\begin{array}{l}\text { Spain: Cooperatives of Sustainable } \\
\text { Consumption and Production }\end{array}$ & & $\begin{array}{l}\text { Belonging to the Galician Network } \\
\text { of Conscious and Responsible } \\
\text { Consumption; engaging local } \\
\text { Zocamiñoca, a responsible consumption } \\
\text { cooperative with focus on food }\end{array}$ \\
$\begin{array}{l}\text { Amarante Setem, promoting sustainable and focusing on local } \\
\text { textiles and fair-trade }\end{array}$ & $\begin{array}{l}\text { Responsible consumption production } \\
\text { and }\end{array}$ & \\
\hline
\end{tabular}




\begin{tabular}{|c|c|c|}
\hline $\begin{array}{l}\text { Equus Zebra, NGO working with } \\
\text { Environmental and Social Sustainability }\end{array}$ & & $\begin{array}{l}\text { Engaged with recovering and re- } \\
\text { using second-hand clothing, } \\
\text { appliances and furniture }\end{array}$ \\
\hline $\begin{array}{l}\text { Romania: Eco-villages } \\
\text { Aurora, Amonia Brassovia }\end{array}$ & $\begin{array}{l}\text { Broad sustainably focus: } \\
\text { Responsible consumption, } \\
\text { food, mobility, housing, } \\
\text { energy, work-leisure balance }\end{array}$ & $\begin{array}{l}\text { Intentional Community, built on the } \\
\text { principles of permaculture, down- } \\
\text { shifting and a sharing economy }\end{array}$ \\
\hline $\begin{array}{l}\text { Italy: Food Cooperatives } \\
\begin{array}{l}\text { Particpant groups include CoRAgGio, } \\
\text { CoBrAgOr, Associazione Parco } \\
\text { AgricoloCasal del Marmo, Terra!, daSudv }\end{array}\end{array}$ & $\begin{array}{l}\text { Food consumption and } \\
\text { production }\end{array}$ & $\begin{array}{l}\text { Production and distribution of food } \\
\text { as well as offering services } \\
\text { (agricultural training and } \\
\text { experimentation, didactics, } \\
\text { workshops, urban gardening, food } \\
\text { services, restoration, green tourism, } \\
\text { and outdoor sports). }\end{array}$ \\
\hline $\begin{array}{l}\text { Germany: Transition Town Networks } \\
\text { Members of Transition Town Halle } \\
\text { Lebensmittel retten Magdeburg }\end{array}$ & $\begin{array}{l}\text { Broad sustainability focus. } \\
\text { Responsible consumption, } \\
\text { focus on local food } \\
\text { production, food sharing and } \\
\text { community-supported } \\
\text { agriculture. }\end{array}$ & $\begin{array}{l}\text { The Transition Town is a social } \\
\text { movement raising awareness and } \\
\text { creating spaces for social, } \\
\text { environmental and economic } \\
\text { sustainability. Lebensmittel retten is } \\
\text { part of the Transition Town } \\
\text { movement, working specifically } \\
\text { with sustainable food. }\end{array}$ \\
\hline
\end{tabular}

The members from the initiatives were recruited through electronic mailing lists referred by fellow members. The non-member sample was recruited in a multi-stage process with a phase of contacting participants via a snowball-system (ES, RO and IT) and an external contractor (DE). Thus, there may be some demographic representation bias associated with the recruitment of our samples. Compared to regional official statistics, our non-member sample appear to over-represent females and younger people. Females are generally associated with lower food- and transportrelated emissions ${ }^{30}$ meaning that we may misestimate the average emission levels in these domains. Age is positively associated with food- and housing-related emissions, and negatively associated with mobility emissions ${ }^{30}$. See SI1 for a detailed discussion on the representativeness of our nonmember samples.

\section{Survey}

We developed a standardized questionnaire to gather self-reported data on environmentally relevant behaviors, consumption, socio-economic and demographic status, life satisfaction and living standards. The survey was first set up in English, followed by translations and adaptations to the official languages of each region. Most items of the questionnaire were kept identical, with regional adaptations being included for socio-demographic variables, in order to respect the contextual conditions of each region. 
We ran a pilot study in the regions of Galicia $(n=94)$ and Saxony-Anhalt $(n=50)$ in order to test for clarity, comprehension and validity of items. The final survey was distributed as an online questionnaire between the months of December 2015 and February 2016. Additional detail on the survey can be found in SI2.

Self-reported data may be a subject to bias when respondents align responses with social norms or identity $^{50,57}$. However, we did not expect this bias to substantially influence our results. First, the carbon footprints at the domain level are not based of single-item measures but rather combine multiple diverse variables (SI3). Additionally, the survey included cross-check items to test for coherence and bias (e.g., annual kilometers registered in the odometer should approximate weekly car travel survey). Thus, for a domain-level result to be critically biased, a diverse set of behaviors, household characteristics and consumption activities would have to be manipulated by a large number of respondents. We expect the potential self-reporting biases towards socially desirable behavior to be relatively consistent across respondents ${ }^{31}$.

We used the Satisfaction with Life scale to measure the cognitive component of subjective wellbeing. The scale consists of five life satisfaction (LS) items (LS1-5). It was developed to indicate overall subjective life satisfaction beyond objective indicators of material well-being ${ }^{58}$. The following statements were evaluated by respondents with a seven point scale from (1) Totally Disagree to (7) Totally agree: LS1: In most ways my life is close to ideal, LS2: The conditions of my life are excellent, LS3:I am satisfied with my life, LS4:So far I have gotten the important things I want in life, LS5:If I could live my life over again, I would change almost nothing. Variable scales and definitions are documented in the SI4.

Comparing individuals through subjective well-being indicators is subject to the caveats of crosscultural analysis, where cultures and worldviews influence self-assessments ${ }^{59}$. However, the LS indicator has been widely tested and proven robust ${ }^{12,14}$, especially for comparing groups of similar cultural background ${ }^{60,61}$. We choose to analyze the individual items instead of aggregating the LS scale, which has been suggested for greater transparency of results ${ }^{61}$.

\section{Methods}

\section{Carbon footprint}

We designed a carbon footprint (CF) model to capture most of the GHG emissions, according to prior carbon assessments of household consumption in the European Union ${ }^{2,20}$. We quantify the CF of food, clothing, housing and mobility, domains that capture the majority of household environmental impacts in Europe ${ }^{2,20}$. Due to survey length constraints, we did not capture details on the consumption of manufactured products and services, as these categories are composed of a wide range of goods (e.g., education, insurances, computers, white goods, etc.). Omitting manufactured products and services, our assessment encompasses between $65-81 \%$ of total household CF across the studied geographical areas ${ }^{2}$. Our calculations were not based on one type of measure, but on considering behavioral, living standards and expenditure variables, as described below and at length in SI3.

We calculated the carbon footprint of food based on dietary habits and weekly frequency of consumption of certain food products. We then approximated daily intake estimates by using the 
EFSA Comprehensive European Food Consumption database ${ }^{62}$, which reports country-specific data on kilograms of food product intake per kilograms of body mass (e.g., meat, dairy products, vegetables and fruits) ${ }^{62}$ and normalized with the respondents' weight to approximate food intake by product ${ }^{63}$. We disregarded metabolic differences for sexes, activity levels and age cohorts, which could be incorporated in future assessments ${ }^{63}$. We conducted a literature review on lifecycle assessments to calculate product-specific carbon intensities per kilogram of product intake to calculate the individual carbon footprint of food intake per person. We used expenditure on storebought food to estimate the impacts associated with the food products that were not covered directly in the survey: processed food, fish, beverages and dry legumes. We coupled expenditure on these items with regionalized monetary carbon intensities from EXIOBASE2.3 ${ }^{2,64}$ (see SI3 for further detail). We enquired about regular clothing spending and applied regionalized monetary carbon intensities ${ }^{2}$ while discounting the share of second-hand consumption, and thus assigning impacts only to purchases of new clothing.

Electricity impacts were derived from reported monthly payments in winter and summers, prices per $\mathrm{kWh}$ and country-level carbon intensities from Eco-Invent $2.2^{65}$. We used a model for space heating based on climate and building characteristics. We derived the effects from typical energy demand in archetypical buildings in Europe, reported by the TABULA project ${ }^{66}$. Theoretical energy demand $\left(\mathrm{kWh} / \mathrm{m}^{2}\right.$-annum) was estimated based on the (1) type of house, (2) year of construction, (3) level of insulation and (4) climate zone of the region. Total space heating needs per person were calculated according to dwelling surface and normalized per person according to household size. The hot water demand was calculated in function of occupants for a European household. GHG emissions of hot water and space heating consider the heating technologies and fuels used by the household ${ }^{66}$. See SI3 for details on housing energy calculations and emission factors.

We based transport footprints on air and land travel. Respondents reported weekly travel patterns, specific transport mode for each trip, number of return trips, approximate distance per trip, purpose of the commute (work vs private trips), and carpooling. Air travel was based on annual number of short- and long-haul flights. We derived lifecycle multipliers per km-passenger from a literature review to apply to transport mode. We calculated specific emission factors per kilometer for private vehicles considering vehicle type, size and fuel (see SI for further detail). We calculated annual CF per capita in 2015 in carbon equivalents (see SI3). The magnitude and shares of calculated emissions across consumption domains align with previous top-down regional assessments ${ }^{2}$. We reported all data exclusions, measures, footprint validations, and input data for the footprint model in the SI3.

\section{Analysis}

Because all the initiatives share a focus on working towards the SDG12 by engaging in sustainable consumption, we study members of all these initiatives as a group. We do so by controlling for socio-economic variables and country differences, in order to isolate the effect of initiative membership. We used descriptive statistics, parametric and non-parametric tests of central tendencies, and multiple regression modelling to compare differences between initiative members and control regions in terms of individual CF. We examined the distribution of CF by consumption domains across initiative members and non-members, and across geographical areas (see SI4). We particularly examined the means and 95\% Confidence Intervals and tested the CF difference using 
a set of one-sided two-sample t-tests. In addition, we performed Wilcoxon rank-sum test and a nonparametric test on the equality of the medians to address concerns about differences in sample sizes (see SI4), and propensity score matching analysis (see SI5).

We further examined the INITIATIVE effect when controlling for socio-demographics and country fixed effects (ES, RO, IT). We performed OLS multiple regression analyses ${ }^{2,20}$ using Stata 14 on a domain (Table 2) and sub-domain level (SI5). See SI4 and SI5 for variable definitions and model specification. We included logarithm transformed footprint values as dependent variables to tackle systematic obtain normal residuals (SI5). Furthermore, a log-transformation may be especially meaningful as different geographical regions in our sample are associated with substantially different footprints, which encouraged us to communicate marginal changes in percentage terms rather than in absolute magnitudes. The analysis was performed on annual per capita footprints. We examined main assumptions behind the regression analysis, analyzed pairwise correlations and multicollinearity, and measured practical and statistical significance of the INITIATIVE effect using multiple smile plots by geographical area (see SI5). The specified model is as follows, where CF estimates vary by consumption domain:

$$
\begin{aligned}
& \ln \left(\widehat{C F}_{i}\right) \\
& =\beta_{0}+\beta_{1}\left(I_{N I T I A T I V E}\right)+\beta_{2}\left(I_{N C O M E_{i}}\right)+\beta_{3}\left(H_{H S I Z E_{i}}\right)+\beta_{4}\left(F E M A L E_{i}\right)+\beta_{5}\left(A G E_{i}\right)+\beta_{6}\left(E D U C_{i}\right)+\beta_{7}\left(R U R A L_{i}\right) \\
& +\beta_{8}\left(\text { MARRIED }_{i}\right)+\beta_{11}\left(E S_{i}\right)+\beta_{12}\left(R O_{i}\right)+\beta_{13}\left(I T_{i}\right)+\epsilon_{i}
\end{aligned}
$$

Finally, we conducted ordinal logistic (logit) regressions using each life satisfaction items as the dependent variable to examine the effect of initiative membership on well-being (see SI5 for assumptions, odds ratios and average marginal effects of initiative membership).

\section{Results}

\section{Carbon footprint of initiative members and non-members}

On average, initiative members have $17 \%$ lower average CF relative to non-members, with 7.8 versus $9.3 \mathrm{tCO}_{2}$ eq/cap. Results from an independent one-sided $t$-test suggest that initiative members have significantly lower total $\mathrm{CF}(t=2.34, P=0.010)$. Across quartiles, initiative members have 7\% (Q1), 11\% (median) and 20\% (Q3) lower total CF (Fig 1). 


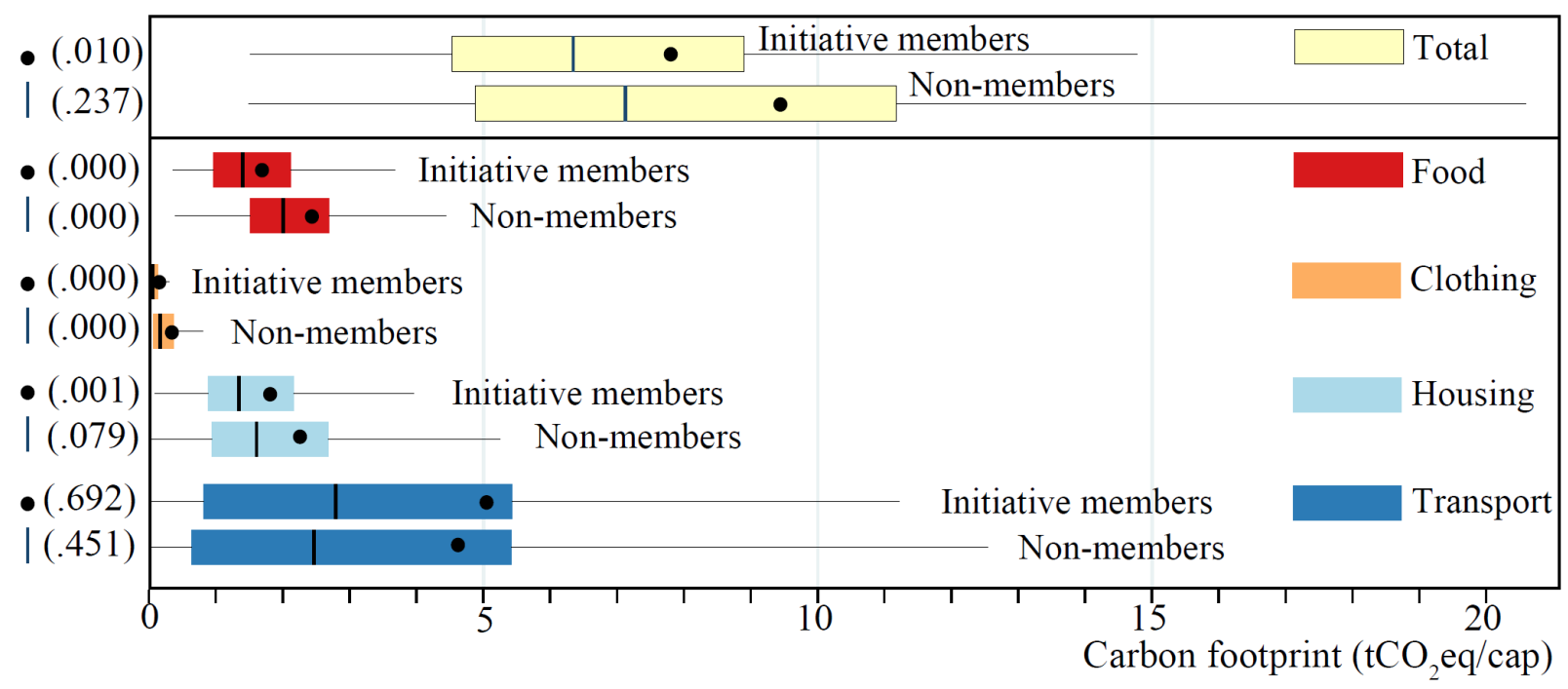

Figure 1| Distribution of annual carbon footprint by consumption domain (in $\mathrm{tCO}_{2} \mathrm{eq} / \mathrm{capita}$ ) of initiative members and nonmembers. Dots - represent mean values and lines $\mid$ represent medians. Boxes describe the 25th percentile (left hinge), and 75 th percentile (right hinge). Whiskers describe the minimum and maximum values in the absence of outliers ( $\pm 1.5 \mathrm{x}$ Interquartile range). Outside values are excluded. $\mathrm{P}$ values (on the left) indicate the significance of mean (one-sided two-sample $t$-test) and median (equality of medians nonparametric test) CF differences between initiative members and non-members regions. See the SI4-5 for more detailed data overview and statistical tests.

By consumption domain, initiative members have lower food and clothing $\mathrm{CF}$ across quartiles (Fig 1). The average food $\mathrm{CF}$ for members is $1.6 \mathrm{tCO}_{2} \mathrm{eq} / \mathrm{cap}$, compared to $2.4 \mathrm{tCO}_{2} \mathrm{eq} /$ cap for the nonmembers $(t=5.50, P=0.000)$. For clothing, the average $\mathrm{CF}$ is 0.1 and $0.3 \mathrm{tCO}_{2} \mathrm{eq} / \mathrm{cap}$ for initiative members and non-members, respectively $(t=13.13, P=0.000)$. Similarly, the results indicate that the medians of the two samples are statistically different. We do not find a similar pattern for housing and transport. The members' average $\mathrm{CF}$ is 1.8 and $5.0 \mathrm{tCO}_{2} \mathrm{eq} / \mathrm{cap}$ for housing and transport, respectively (compared to 2.2 and $4.6 \mathrm{tCO}_{2} \mathrm{eq} / \mathrm{cap}$ for non-members). Although the $t$-test points to significant differences in housing CF between the samples, the result is likely influenced by inter-group differences in socio-demographics, such as income and urbanization as discussed below.

\section{Isolating the membership effect from socio-demographic factors}

We perform multiple regression analyses to compare the CF of initiative members with their sociodemographic regional counterparts (Table 2). The estimated models include the natural $\log$ transformed values of total and domain-specific $\mathrm{CF}$ as dependent variables. The independent variables are initiative membership (INITIATIVE), income (INCOME), and additional sociodemographic factors, which are controlled for in order to measure differences across comparable individuals. Country-specific fixed effects were included to control for the potential cultural and contextual factors shared by co-nationals. Thus, the INITIATIVE coefficient is interpreted as the percentage change in the domain-specific footprint associated with initiative membership, holding everything else constant. A negative and significant coefficient would be favorable from a climate change mitigation perspective, as it suggests an actual CF reduction. We report $95 \%$ Confidence Intervals (CI) in parenthesis. Our model and the choice of additional socio-demographic controls has been motivated by prior literature, particularly income level, education, gender, family status, age, urban typology and household $\operatorname{size}^{2,29,50,67}$. A detailed description of the effects and their expected direction can be found in the model background (SI5). 


\begin{tabular}{|c|c|c|c|c|c|c|c|c|c|c|}
\hline & \multicolumn{2}{|l|}{ Total CF } & \multicolumn{2}{|l|}{ Food CF } & \multicolumn{2}{|c|}{ Clothing CF } & \multicolumn{2}{|c|}{ Housing CF } & \multicolumn{2}{|c|}{ Transport CF } \\
\hline & Total & Initiatives & Total & Initiatives & Total & Initiatives & Total & Initiatives & Total & Initiatives \\
\hline \multirow{2}{*}{ INITIATIVE } & $-0.155^{* *}$ & & $-0.425^{* * *}$ & & $-0.857 * * *$ & & $-0.124 *$ & & -0.082 & \\
\hline & (0.07) & & $(0.05)$ & & $(0.13)$ & & $\begin{array}{l}(0.07) \\
\end{array}$ & & $(0.16)$ & \\
\hline \multirow[t]{2}{*}{ INCOME } & $0.27^{* * *}$ & 0.104 & $0.048^{* * *}$ & -0.016 & $0.225^{* * *}$ & 0.136 & $0.045^{* *}$ & -0.074 & $0.248^{* * *}$ & $0.282 *$ \\
\hline & $(0.02)$ & $(0.06)$ & $(0.01)$ & $(0.05)$ & $(0.03)$ & $(0.14)$ & $(0.02)$ & $(0.08)$ & $(0.04)$ & $(0.16)$ \\
\hline \multirow[t]{2}{*}{ HHSIZE } & $-0.050 * * *$ & -0.021 & $-0.010^{*}$ & $-0.041^{*}$ & $-0.061 * * *$ & $-0.236^{* *}$ & $-0.115 * * *$ & $-0.125^{* * *}$ & -0.028 & 0.052 \\
\hline & $(0.02)$ & $(0.03)$ & $(0.01)$ & $(0.02)$ & $(0.02)$ & $(0.11)$ & $(0.03)$ & $(0.05)$ & $(0.02)$ & $(0.06)$ \\
\hline \multirow[t]{2}{*}{ FEMALE } & $-0.119 * * *$ & -0.198 & $-0.179 * * *$ & $-0.165^{*}$ & 0.026 & -0.083 & -0.007 & -0.097 & $-0.227^{* * *}$ & $-0.662 * *$ \\
\hline & $(0.03)$ & $(0.13)$ & $(0.02)$ & $(0.09)$ & $(0.06)$ & $(0.25)$ & $(0.04)$ & $(0.11)$ & $(0.08)$ & $(0.31)$ \\
\hline \multirow[t]{2}{*}{ AGE } & 0.039 & -0.053 & $0.064 * * *$ & $0.183 * *$ & $0.103^{* *}$ & $0.380^{*}$ & $0.227 * * *$ & $0.246^{* *}$ & $-0.113 *$ & $-0.554^{*}$ \\
\hline & $(0.03)$ & $(0.14)$ & $(0.02)$ & $\begin{array}{l}(0.09) \\
\end{array}$ & $(0.05)$ & $(0.21)$ & $(0.04)$ & $(0.11)$ & $(0.06)$ & $(0.28)$ \\
\hline \multirow[t]{2}{*}{ EDUC } & $0.057 * * *$ & -0.078 & $-0.024 * * *$ & -0.121 & $0.077^{* *}$ & -0.132 & -0.000 & 0.157 & $0.140^{* * *}$ & 0.028 \\
\hline & $(0.01)$ & $(0.12)$ & $(0.01)$ & $(0.08)$ & $(0.03)$ & $(0.15)$ & $(0.02)$ & $(0.11)$ & $(0.04)$ & $(0.21)$ \\
\hline \multirow[t]{2}{*}{ RURAL } & $0.069 * * *$ & 0.050 & 0.003 & -0.051 & -0.017 & $-0.677 * * *$ & $0.089 * * *$ & $-0.210^{*}$ & $0.171^{* * *}$ & 0.010 \\
\hline & $(0.02)$ & $(0.09)$ & $(0.01)$ & $(0.07)$ & $(0.04)$ & $(0.16)$ & $(0.03)$ & $(0.12)$ & $(0.05)$ & $(0.21)$ \\
\hline \multirow[t]{2}{*}{ MARRIED } & -0.026 & 0.017 & $0.099 * * *$ & $0.184^{*}$ & -0.016 & -0.169 & $-0.157 * * *$ & 0.036 & 0.049 & -0.050 \\
\hline & $(0.04)$ & $(0.16)$ & $(0.02)$ & $(0.11)$ & $(0.07)$ & $(0.25)$ & $(0.05)$ & $(0.14)$ & $(0.09)$ & $(0.32)$ \\
\hline Country effects & YES & YES & YES & YES & YES & YES & YES & YES & YES & YES \\
\hline AdjustedR $^{2}$ & 0.131 & 0.046 & 0.293 & 0.332 & 0.183 & 0.204 & 0.226 & 0.157 & 0.069 & 0.175 \\
\hline Obs. & 1499 & 92 & 1569 & 104 & 1432 & 96 & 1607 & 132 & 1446 & 117 \\
\hline \multicolumn{11}{|c|}{$\begin{array}{l}\text { Unstandardized beta coefficients and robust standard errors in parenthesis. Dependent variables in logarithmic form, by consumption domain. } \\
\text { Country-specific fixed effects and constant included. Significance level: }{ }^{*} \mathrm{p}<0.1, * * \mathrm{p}<0.05,{ }^{* *} \mathrm{p}<0.01 \text {. See SI for further detail on independent } \\
\text { variables and correlation tests and for regression output for the non-member sample. The total sample includes initiative members and non- } \\
\text { members. }\end{array}$} \\
\hline
\end{tabular}

We find an INITIATIVE coefficient of $-0.16(-0.29,-0.02)$, pointing to a significant (at the $5 \%$ level) difference between initiative members and non-members in terms of total CF (Table 2). The effect is stronger for food and clothing, $-0.43(-0.52,-0.33)$ and $-0.86(-1.11,-0.60)$, indicating that members have about $43 \%$ and $86 \%$ lower food and clothing CF, respectively. The INITIATIVE coefficient is insignificant at the 5\% significance level for housing and transport, reflecting similarities between initiative members and non-members in these domains. Our model explains between $7-29 \%$ of the variance $\left(\mathrm{Adj} . \mathrm{R}^{2}\right)$ in the $\mathrm{CF}$ across consumption domains for the total sample (Table 2).

Figure 2 confirms inter-group emission differences on a sub-domain level. Although initiative members exhibit a $23 \%$ higher $\mathrm{CF}$ in vegetables and fruits, this increase is outweighed by a $32 \%$ lower CF of meat, $31 \%$ lower CF of dairy products, and 33\% lower CF of miscellaneous foods (Fig 2). The lower CF of initiative members reflects the combined effect of lower expenditure in food and clothing, and lower carbon intensity of consumption due to dietary differences (less frequent consumption of meat, dairy products and processed food) and a higher share of second-hand clothing (SI5).

Our findings for housing and transport are consistent on a sub-domain level, with insignificant INITIATIVE coefficients for CF associated with consumption of electricity, space and water heating, land and air travel (Fig 2). We find no differences between initiative members and their socio-demographic counterparts in terms of dwelling characteristics, living surface, electricity consumption, heating demand and systems, commuting distance, car ownership, and number of long-and short-flights.

Domain-specific differences between initiative members and non-members may be explained by the constraints associated with specific low-carbon behaviors ${ }^{30,68}$. While decisions around diets and clothing may better reflect individual preferences, mobility and housing choices are often 
constrained by long-lived infrastructure, urban design, public transport options, and commuting distances ${ }^{4,68}$. This trend has been identified as a behavioral paradox: "the greater the $\mathrm{CO}_{2}$ reduction potential of mitigation actions, the less households are willing to implement them...because

they imply a greater lifestyle change." ${ }^{\prime 68}$ (p. 150). It is worth noting that we find significant behavioral differences even within the more structurally-constrained domains of housing and mobility behaviors ${ }^{30}$, with initiative members tolerating lower home temperatures in the winter $\left(\beta=-0.9, p<.01\right.$, unit: preferred room temperature in $\left.{ }^{\circ} \mathrm{C}\right)$ and commuting more by cycling and walking $(\beta=1786, p=.013$, unit: annual $\mathrm{km})(\mathrm{SI} 5)$.

The difference that we find between initiative members and non-members in terms of carbon footprint appears conservative compared to prior studies. For example, Daly (2017) found that the average reduction in carbon contribution of intentional communities was about $35 \%{ }^{53}$. Howell (2012) reported a similar reduction for members of a voluntary carbon allowance initiative ${ }^{54}$. These studies surveyed initiatives with the explicit goal to reduce overall environmental impact, while our sample covers a wider range of initiatives and goals. Noteworthy, these studies did not control for socio-economic variables. Further, the studies did not employ a consistent carbon footprint calculator across participants.

Our findings of 16\% reduction (regression coefficient, Table 2) in GHG emissions driven by changes in diet and fashion consumption of initiative members align with the reduction potential from lifestyle changes at the macro-level ${ }^{35}$. Shifting to vegetarian diets is associated to a $6 \% \mathrm{CF}$ reduction, while adopting a full plant-based diet could reduce European household emissions by $14-16 \%{ }^{35}$. Preferring locally produced fashion could yield $0.5 \%$ reduction, while re-using and extending clothing lifetime could yield about $2 \%$ emission reduction ${ }^{35}$. Naturally, a bulk of reduction potential remains within the housing and transport domains ${ }^{2,35}$, as discussed in the limitations and policy sections.

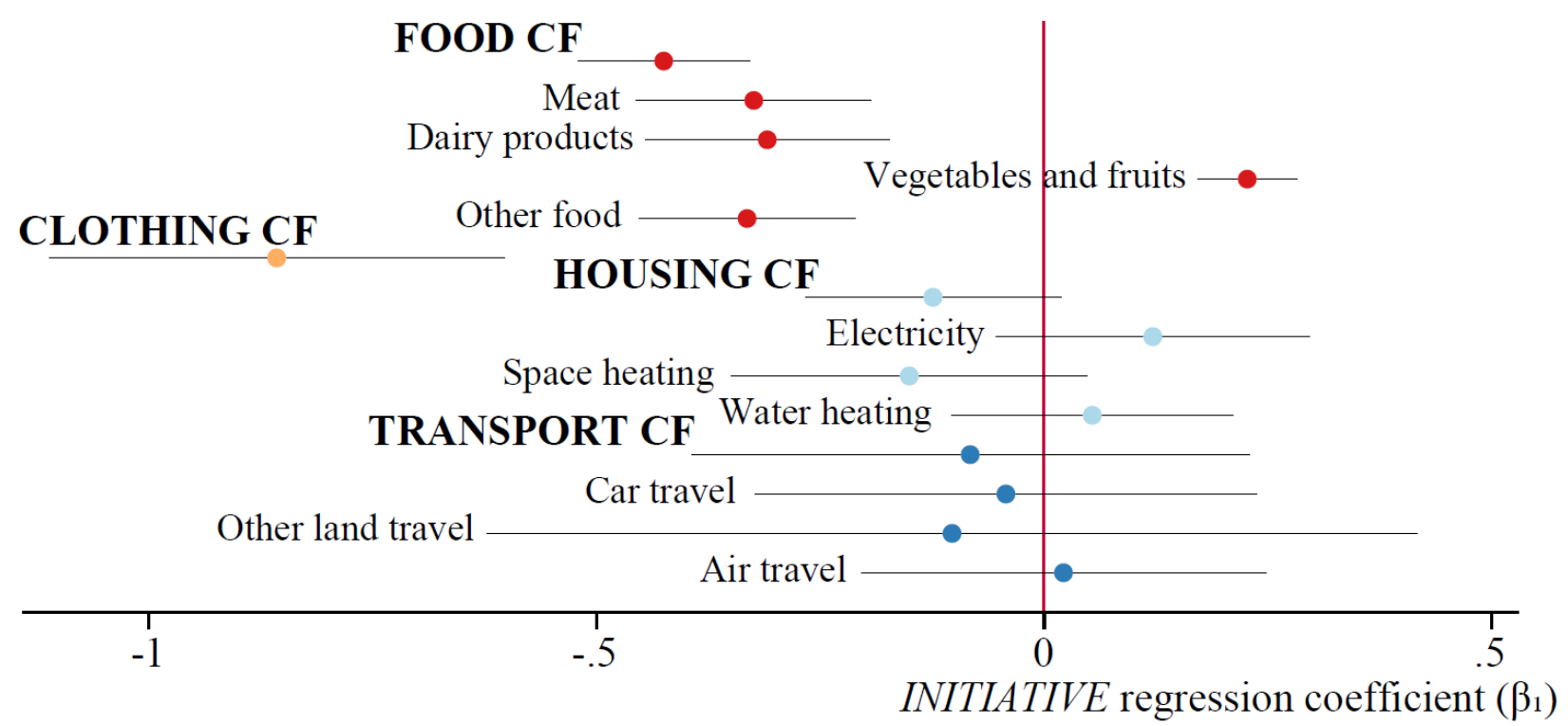

Figure 2: Sub-domain INITIATIVE regression coefficients (dots) incl. 95\% CI (whiskers). Carbon footprint (CF) by consumption domains and sub-domains. See the method section for regression equation and SI5 for full output. Key: When zero is included in the CI, one cannot conclude significant differences in the CF of initiative members for that sub-domain. Other food 
includes processed food, beverages, fish products, and dry legumes. Color coding highlights the different consumption domains food, clothing, housing and transport.

We confirm income as a significant driver of CF for the total sample ${ }^{2,4,69}$. The shift to a higher income class is associated with a $23 \%$ and $25 \%$ increase in the CF of typically income-elastic domains such as clothing and mobility ${ }^{20}$ (Table 2). The same shift is associated with a $5 \%$ increase in the $\mathrm{CF}$ of food and housing, reflecting the low income elasticity of domains that serve basic needs ${ }^{20}$.

Yet changes in income class (INCOME) do not explain variation in the $\mathrm{CF}$ for initiative members in any of the consumption domains. The INCOME effect is no longer significant for initiative members (except the partially significant coefficient for transport). In terms of consumption and behavior, for initiatives, higher income does not imply higher expenditure on food, clothing and electricity, car ownership or increased travel. Instead, we find other socio-demographic variables such as household size ${ }^{67,69}$, gender ${ }^{67}$, and age ${ }^{67,69}$, and country-specific fixed effects ${ }^{2,69}$ to have a higher explanatory power for the members' CF variation across consumption domains (Table 2). SI figure 2 provides more detail into the income distribution of the initiative member and nonmember samples, which appears approximately normally distributed.

\section{Life satisfaction of initiative members and non-members}

Finally, we screened for differences in life satisfaction ${ }^{58}$ between samples to test whether reduced $\mathrm{CF}$ jeopardizes well-being ${ }^{9,16}$. We confirmed that the lower $\mathrm{CF}$ for initiative members is not associated with lower life satisfaction; on the contrary, members scored even higher across most items of the life satisfaction scale. We conducted ordinal logistic regressions and displayed marginal effects with regards to the INITIATIVE coefficient (Fig 3).

We find highly significant inter-group life satisfaction (LS) differences for three of the five items (LS1-3), and partially significant for LS5. Initiative members are 7-9\% less likely to evaluate their life negatively by disagreeing with life satisfaction statements (Fig 3, aggregating effects in red and orange for LS1-3). Members are also 11-13\% more likely to evaluate their life positively (Fig 3, aggregating effects in blue for LS1-3).

A recent qualitative study derived from the same project (GLAMURS) presented evidence of a positive association between grassroots membership and several dimensions of well-being: selfacceptance, personal growth, purpose in life, environmental mastery, autonomy, and positive relations with others ${ }^{46}$. Our findings provide quantitative evidence that lower consumption CF and higher life satisfaction are compatible for members of grassroots initiatives. Although lifesatisfaction is a broad indicator, it has been positively correlated with all of the aforementioned dimensions of well-being ${ }^{14,60}$.

Previous studies reported negative associations between higher CF and life-satisfaction ${ }^{40,51,52}$, and positive associations between initiative membership and life-satisfaction ${ }^{40,47,48}$. They explain this trend through several mechanisms. First, the positive effects of being intrinsically motivated and making conscious lifestyle choices ${ }^{47,70}$. Second, from an evolutionary perspective, small-scale, tribal communities are associated with higher "mental health" and satisfied social needs ${ }^{55}$. Third, social and economic capital are to some extent interchangeable ${ }^{71}$, thus the richer social capital observed in these groups have been proposed to obviate the need for built capital or consumption $^{14,48}$. Finally, materialistic (extrinsically motivated) individuals have been associated 
with lower life satisfaction, fewer environmentally friendly behaviors, and higher $\mathrm{CF}^{40,51}$. On the contrary, altruistic behaviors, including volunteering, are positively associated with proenvironmental behaviors, higher well-being and lower $\mathrm{CF}^{47,50,52}$.

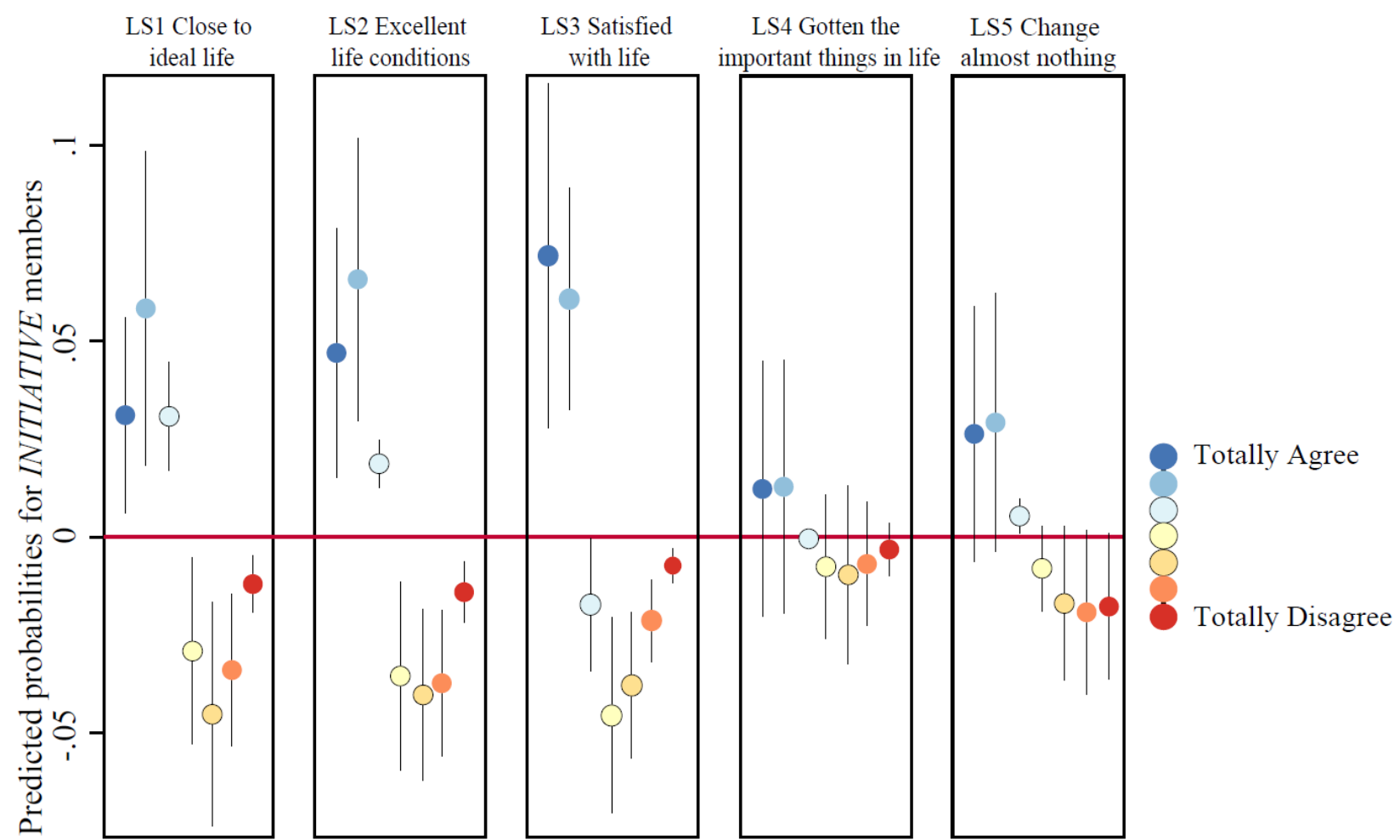

Figure 3: Predicted probabilities (average marginal effects) for Life Satisfaction (LS) of initiative members incl. 95\% CI (whiskers). Based on ordinary logistic regression across the five LS items. Each LS item (dependent variable) is measured on a 7point scale from "Totally disagree" (in red, indicating low life satisfaction) to "Totally agree" (in blue, indicating high life satisfaction). Key: When zero is included in the CI, one cannot conclude significant differences in the LS of initiative members. Odds ratios included in SI5.

\section{Limitations and future work}

There are some limitations with regards to the type of initiatives sampled. Our sample includes comprehensive grassroots initiatives such as the Transition Town movement and eco-villages, but lacks initiatives specialized in housing and mobility e.g., co-housing, downsizing, car sharing, cycling ${ }^{17}$. Thus, our results are not conclusive in these domains and further investigation of such initiative niches is needed. Particularly, the domain of transport stands out with its high importance for consumption-based emissions, and hence further exploration is key ${ }^{30}$. Similarly, no sampled initiatives target electronic appliances and devices. Initiatives such as Repair Cafés, where people develop repairing skills and swap appliances, may yield reductions in the CF of manufactured products. Manufactured products and services have been discussed as income elastic; that is, we expect stronger emission increases in these domains as income increases, compared to basic goods such as food and energy ${ }^{2,20,72}$. Further exploration of the INCOME effect for initiative member with regards to highly elastic goods is needed to conclude on the income-footprint relationships and its implications in other consumption domains. Our assessment is focused on carbon -however other resource savings might be associated with initiative membership. Members consume significantly less food and clothing, which are particularly water and land intensive ${ }^{20}$. Thus, consumer-side shifts in these domains will be relevant even under a low-carbon energy scenario. Even though initiatives membership is associated with lower climate impacts, the observed reductions are insufficient to 
bring European consumption within planetary boundaries ${ }^{12}$. The average CF of initiative members is still about five times higher than the per capita quota of $1.6 \mathrm{tCO}_{2} \mathrm{eq}^{12}$ and further efforts are required to reach the target.

Nevertheless, initiative members show 16\% lower carbon footprints compared to non-members, and demonstrate substantially different consumption patterns such as higher adoption of vegetarianism, cooler housing, and lower reliance on car travel and other consumption (SI5). While these point to potential constraints of low-carbon activities, they may also point to opportunities. Investigating low-carbon adaptations such as better insulated housing and working from home lie beyond this study, although there may be substantial differences in their adoption rates between members and non-members.

We use LS scale as an indicator for well-being, which has been widely used and thus enables comparison with previous literature ${ }^{12,14,60,61,73,74}$. While the LS has proven cross-cultural validity $^{61,75}$, the challenge remains to empirically determine the relative weight of universal and personal factors that influence $\mathrm{LS}^{61,74}$. Given the strong influence of basic material needs, the adequacy of LS to represent well-being has been questioned as it is not a guarantee of mental nor emotional health ${ }^{76}$. Beyond living standards, recent studies find that fundamental human needs such as freedom, relatedness and mastery explain differences in LS between individuals of similar material well-being ${ }^{60,61,74}$

Both research on well-being and environmental protection are turning to assessing fundamental human needs directly rather than aggregated measures of well-being ${ }^{14,60,77}$. Grassroots initiatives have been described as synergistic need satisfiers due to the wide range of needs they might simultaneously address: social connection, creativity, learning, self-acceptance, productive leisure and, in some cases, basic needs such as quality food and housing ${ }^{37}$. Future research could explore specific needs in relation to membership ${ }^{14}$ and to different lifestyle changes ${ }^{35}$.

Because LS can be affected by peoples' escalating desires and standards ${ }^{61}$, a focus on fundamental needs is more compatible with mitigation and adaptation strategies ${ }^{77}$. A needs-centered view on sustainable developments calls for rationing resources only where they prove to satisfy needs ${ }^{14,77}$. In this sense, grassroots initiatives might be a resource-efficient strategy to satisfy fundamental needs ${ }^{14}$.

\section{Uncertainty and validation}

We explored footprint distributions and regression results, particularly INITIATIVE and INCOME coefficients, across the four regions and confirmed that the patterns discussed in the main text generally hold across regions (see SI5). More detailed graphs depicting how the different regions compare in terms of the practical and statistical significance of the INITIATIVE coefficients in the food, clothing, housing and transport domains can be found in SI5. While some differences are noted across regions, the INITIATIVE coefficients are of high practical and statistical significance for all sampled regions. Further, the observed trend of the INITIATIVE effect on CF holds true for consumption and behavioral variables (see SI5).

In addition, we test robustness of our main statistical results (see SI5). Seven of the 12 sampled initiatives are particularly focused on the production, distribution or consumption of food (see Methods). We ran the regression model separately for food-specific and other initiatives and observe similar trends of the INITIATIVE effect across domains and overlapping 95\% confidence intervals. This suggests evidence for a "positive spillover", or consistency in the lifestyles of 
members, regardless of the main focus of the initaitve ${ }^{23}$. This validation step also supports the observation that clothing and food might be domains where lifestyle decisions are more directly reflected, whereas housing and mobility are rather constrained by context ${ }^{30,68}$.

We conducted several uncertainty checks to test the assumptions behind our footprint calculations, e.g. flight distance (SI 3.6). Our survey-based CF values for individuals are within the range reported by prior CF per capita assessments of regional household consumption ${ }^{2}$. Domain-level footprint calculations were validated against domain-specific CF of EU regions (see SI3).

We further compared our results obtained through multivariate regression with propensity score matching analysis, which by reducing the covariates into a single score, reduces confounding bias and adds certainty to our results. The coefficients from the propensity score matching analysis were comparable to our regression estimates, with all OLS regression coefficients contained in the estimates $95 \%$ confidence intervals.

\section{Policy Implications}

Despite the overall behavioral changes, the CF reduction of members was moderate and confined to the domains of food and clothing. Efforts from the supply side could help reduce the carbon intensity of consumption ${ }^{35}$. Partnerships between policymakers and initiatives could tackle constraints imposed by structural factors, especially in the domains of housing and transport, in order to maximize citizens' opportunities to reduce emissions ${ }^{30,33}$.

Indeed, the Paris Pledge for Action $^{2}$ saw unprecedented willingness to act by non-state stakeholders, including grassroots initiatives and citizen networks, with more than 1,000 non-state initiatives signing their commitment to keep the world well below a $2^{\circ} \mathrm{C}$ trajectory. Although the potential of non-state actions is clearly acknowledged in the official Paris decisions, the mechanisms to support, upscale and embed them into national pledges remain vague ${ }^{17,18,36}$.

Diffusion is the process by which a new technology, idea or behavior is spread among the members of a social system, across different geographies or throughout time ${ }^{24,78}$. Large scale diffusion of grassroots initiatives may lead to social tipping points by offering opportunities for low-impact behaviors and higher social well-being to a wider audience ${ }^{23,24}$. Diffusion can be supported bottomup, as more members engage, or by embedding the initiatives' agendas into institutional strategies 35,39 . Replication or "out-scaling" is another mechanism of diffusion, which happens when similar initiatives emerge in other geographies ${ }^{78,79}$. Finally, translation is the diffusion process through which grassroots innovations are translated to other consumption domains ${ }^{79,80}$.

While initiatives might benefit from collaborations with official institutions in terms of resources and visibility ${ }^{81}$, it might also crowd-out members ${ }^{82}$ or weaken key aspects such as governance, accountability, inclusion and autonomy ${ }^{17,37,39,81}$. Not all initiatives are equal candidates for upscaling ${ }^{81}$. Some grassroots initiatives might aim to remain low-scale and local, and thus diffusion might not be a de-facto goal ${ }^{83}$. Rather than focusing solely on upscaling existing initiatives, policies should consider incubating and supporting emerging initiatives to outlive their typical financial challenges by providing visible physical space, facilitate training and provide financial operating

\footnotetext{
${ }^{2}$ http://www.parispledgeforaction.org/
} 
resources ${ }^{17,37,39}$, as well as support trans-initiative networking efforts ${ }^{84}$.In sum, a sensible strategy to achieve the goals of the Paris Agreement would not solely rely on technological change, but also on ambitious multi-scale policy reforms combined with non-state actions and lifestyle changes that reduce impact and enhance well-being ${ }^{21,35,36}$.

Our results suggests a role for grassroots initiatives in supporting "sustainable de-growth" in Europe $^{11}$. Policies that seek to optimize climate and social goals are not to underestimate the role of grassroots initiatives in creating opportunities for low-carbon well-being. Beyond the statistical differences between members and non-members, initiatives foster new practices that are freely ran by citizens and made available to the wider public. In this sense, sustainably initiatives may have the social function of promoting and enabling sustainable lifestyles, thus paving the way for wider acceptance of $\mathrm{CF}$ reduction policies ${ }^{17}$.

\section{Concluding remarks}

We find members of grassroots initiatives not only to exhibit lower carbon footprints and higher life satisfaction, but also to dissociate consumption emissions from income and well-being. For members, lower consumption is compatible with higher well-being, supporting the notion of voluntary simplicity ${ }^{16,37,40}$. Previous research suggests that voluntary simplicity is positively associated with mindfulness ${ }^{40}$ and that participating in grassroots initiatives spurs self-awareness of underlying values and behavior ${ }^{73}$. Further, engaging in grassroots initiatives might expose participants to a combination of stimuli such as information, setting goals, public commitments, social norms and behavioral feedbacks, all of which can potentially influence behavior, by creating new habits or reinforcing existing ones ${ }^{23,27,29,37,39,49,50}$. In this sense, social learning and group interaction are not only mechanisms through which knowledge and skills are shared, but they also stimulate the questioning of the current narratives of consumption and well-being, including institutional logics, power relations and the goals of the current systems and lifestyles $17,37,43,45,70$.

As social innovations, grassroots initiatives might be more efficient than government or markets at satisfying certain social needs: by offering affordable products such as organic food or renewable energy, creating innovative governance arrangements, establishing alternative economic circuits ${ }^{79}$ or proto-institutions that embed new sustainable lifestyles ${ }^{44}$. Quantifying multi-level, multicriteria, and long-term environmental and social effects of initiatives remains an interesting challenge for future research in this area.

In summary, we find grassroots initiatives membership to shed insights towards the goal of sustainable consumption and production (SDG12) by decoupling footprints from income (SDG8) and reconciling environmental conservation (SDG13-15) with enhanced well-being. We consider grassroots initiatives to be worthy of further research and policy consideration as a strategy for the transformation towards sustainability. 


\section{References}

1. Akenji, L. \& Bengtsson, M. Making sustainable consumption and production the core of Sustainable Development Goals. Sustainability 6, 513-529 (2014). doi:10.3390/su6020513

2. Ivanova, D. et al. Mapping the carbon footprint of EU regions. Environ. Res. Lett. 12, (2017). doi:10.1088/1748-9326/aa6da9

3. Lenzen, M. et al. The carbon footprint of global tourism. Nat. Clim. Chang. 8, 522-528 (2018). doi:10.1038/s41558-018-0141-x

4. Blanco, G. et al. Drivers, Trends and Mitigation. Climate Change 2014: Mitigation of Climate Change. Contribution of Working Group III to the Fifth Assessment Report of the Intergovernmental Panel on Climate Change Chapter 5, (2014).

5. Hatfield-Dodds, S. et al. Australia is 'free to choose' economic growth and falling environmental pressures. Nature 527, 49-53 (2015). doi:10.1038/nature16065

6. (UNEP), U. N. E. P. Decoupling Environmental Resource Use and Economic Growth Summary. (2011). Available at:

http://www.unep.org/resourcepanel/Portals/24102/PDFs/DecouplingENGSummary.pdf\%5Cnpaper s2://publication/uuid/E74B39E8-2ECE-40EB-B447-C245B77DF785.

7. Wiedmann, T. O. et al. The material footprint of nations. Proc. Natl. Acad. Sci. U. S. A. 112, 1-6 (2013). doi:10.1073/pnas.1220362110

8. Wood, R. et al. Growth in Environmental Footprints and Environmental Impacts Embodied in Trade: Resource Efficiency Indicators from EXIOBASE3. J. Ind. Ecol. 22, 553-564 (2018). doi:10.1111/jiec. 12735

9. Victor, P. Questioning economic growth. Nature 468, 370-371 (2010). doi:10.1038/468370a

10. Akenji, L. Consumer scapegoatism and limits to green consumerism. J. Clean. Prod. 63, 13-23 (2014). doi:10.1016/j.jclepro.2013.05.022

11. Martínez-Alier, J., Pascual, U., Vivien, F.-D. \& Zaccai, E. Sustainable de-growth: Mapping the context, criticisms and future prospects of an emergent paradigm. Ecol. Econ. 69, 1741-1747 (2010). doi:10.1016/j.ecolecon.2010.04.017

12. O'Neill, D. W. et al. A good life for all within planetary boundaries. Nat. Sustain. 1, 88-95 (2017). doi:10.1038/s41893-018-0021-4

13. D'Alisa, G., Demaria, F., Kallis, G. \& Nelson, S. K. Degrowth A vocabulary for a new era. (Routledge, 2015). Available at: https://www.routledge.com/Degrowth-A-Vocabulary-for-a-NewEra/DAlisa-Demaria-Kallis/p/book/9781138000773. (Accessed: 18th March 2018)

14. Vita, G., Hertwich, E. G., Stadler, K. \& Wood, R. Connecting global emissions to fundamental human needs and their satisfaction. Environ. Res. Lett. 14, 014002 (2019). doi:10.1088/17489326/aae6e 0

15. Brand-Correa, L. I. \& Steinberger, J. K. A Framework for Decoupling Human Need Satisfaction From Energy Use. Ecol. Econ. 141, 43-52 (2017). doi:10.1016/j.ecolecon.2017.05.019

16. Jackson, T. Live better by consuming less? Is there a 'double dividend' in sustainable consumption? J. Ind. Ecol. 9, 19-36 (2005). doi:10.1162/1088198054084734

17. Seyfang, G. \& Smith, A. Grassroots innovations for sustainable development: Towards a new 
research and policy agenda. Env. Polit. 16, 584-603 (2007). doi:10.1080/09644010701419121

18. Hsu, A. et al. A research roadmap for quantifying non-state and subnational climate mitigation action. Nat. Clim. Chang. doi:10.1038/s41558-018-0338-z

19. Hossain, M. Grassroots innovation: A systematic review of two decades of research. J. Clean. Prod. 137, 973-981 (2016). doi:10.1016/j.jclepro.2016.07.140

20. Ivanova, D. et al. Environmental impact assessment of household consumption. J. Ind. Ecol. 20, 526-536 (2016). doi:10.1111/jiec.12371

21. Creutzig, F. et al. Towards demand-side solutions for mitigating climate change. Nat. Clim. Chang. 8, 268-271 (2018). doi:10.1038/s41558-018-0121-1

22. Taufik, D., Bolderdijk, J. W. \& Steg, L. Acting green elicits a literal warm glow. Nat. Clim. Chang. 5, 37-40 (2015). doi:10.1038/nclimate2449

23. Thøgersen, J. Psychology: Inducing green behaviour. Nat. Clim. Chang. 3, 100-101 (2013). doi:10.1038/nclimate1808

24. Nyborg, K. et al. Social norms as solutions: Policies may influence large-scale behavioral tipping. Science (80-. ). 354, 42-43 (2016). doi:10.1126/science.aaf8317

25. Meadows, D. H. Places to intervene in a system. Hartland: The Sustainabilty Institute (1997). doi:10.1016/0167-188X(89)90098-0

26. O'Brien, K. Political agency: The key to tackling climate change. Science (80-. ). 350, 4-6 (2015). doi:10.1126/science.aad0267

27. Abrahamse, W., Steg, L., Vlek, C. \& Rothengatter, T. A review of intervention studies aimed at household energy conservation. J. Environ. Psychol. 25, 273-291 (2005). doi:10.1016/j.jenvp.2005.08.002

28. Moser, S. \& Kleinhückelkotten, S. Good intents, but low impacts: Diverging importance of motivational and socioeconomic determinants explaining pro-environmental behavior, energy use, and carbon footprint. Environ. Behav. 1-31 (2017). doi:10.1177/0013916517710685

29. Büchs, M. The role of environmental organisations in supporting carbon reduction: comparing direct and indirect involvement. Env. Polit. 23, 1003-1022 (2014).

doi:10.1080/09644016.2014.921456

30. Ivanova, D. et al. Carbon mitigation in domains of high consumer lock-in. Glob. Environ. Chang. 52, 117-130 (2018). doi:10.1016/j.gloenvcha.2018.06.006

31. Balmford, A., Cole, L., Sandbrook, C. \& Fisher, B. The environmental footprints of conservationists, economists and medics compared. Biol. Conserv. 214, 260-269 (2017). doi:10.1016/j.biocon.2017.07.035

32. Ordner, J. P. Community action and climate change. Nat. Clim. Chang. 7, 161-163 (2017). doi:10.1038/nclimate3236

33. Ürge-Vorsatz, D. et al. Locking in positive climate responses in cities. Nat. Clim. Chang. 8, 174 185 (2018). doi:10.1038/s41558-018-0100-6

34. Geels, B. F. W., Benjamin, K., Schwanen, T. \& Sorrell, S. Sociotechnical transitions for deep decarbonization. Sci. Policy Forum 357, 1242-1244 (2017).

35. Vita, G. et al. The Environmental Impact of Green Consumption and Sufficiency Lifestyles 
Scenarios in Europe: Connecting Local Sustainability Visions to Global Consequences. Ecol. Econ. 164, 106322 (2019). doi:10.1016/j.ecolecon.2019.05.002

36. Rogelj, J. et al. Paris Agreement climate proposals need a boost to keep warming well below $2{ }^{\circ} \mathrm{c}$. Nature 534, 631-639 (2016). doi:10.1038/nature18307

37. Grabs, J., Langen, N., Maschkowski, G. \& Schäpke, N. Understanding role models for change: A multilevel analysis of success factors of grassroots initiatives for sustainable consumption. $J$. Clean. Prod. 134, 98-111 (2016). doi:10.1016/j.jclepro.2015.10.061

38. Csutora, M. One More Awareness Gap? The Behaviour-Impact Gap Problem. J. Consum. Policy 35, 145-163 (2012). doi:10.1007/s10603-012-9187-8

39. Feola, G. \& Nunes, R. Success and failure of grassroots innovations for addressing climate change: The case of the Transition Movement. Glob. Environ. Chang. 24, 232-250 (2014). doi:10.1016/j.gloenvcha.2013.11.011

40. Brown, K. W. \& Kasser, T. Are Psychological and Ecological Well-being Compatible? The Role of Values, Mindfulness, and Lifestyle. Soc. Indic. Res. 74, 349-368 (2005). doi:10.1007/s11205004-8207-8

41. Eigner, S. The relationship between "'protecting the environment"' as a dominant life goal and subjective well-being. in Life Goals and Well-Being: Towards a Positive Psychology of Human Striving (ed. Sheldon, in P. S. and K. M.) 182-201 (Hogrefe and Huber, 2001).

42. Grabs, J. The rebound effects of switching to vegetarianism. A microeconomic analysis of Swedish consumption behavior. Ecol. Econ. 116, 270-279 (2015). doi:10.1016/j.ecolecon.2015.04.030

43. Feola, G. Societal transformation in response to global environmental change: A review of emerging concepts. Ambio 44, 376-390 (2015). doi:10.1007/s13280-014-0582-z

44. Frantzeskaki, N. et al. Elucidating the changing roles of civil society in urban sustainability transitions This review comes from a themed issue on System dynamics and sustainability. Curr. Opin. Environ. Sustain. 22, 41-50 (2016). doi:10.1016/j.cosust.2017.04.008

45. Longhurst, N. et al. Experimenting with alternative economies: four emergent counter-narratives of urban economic development. Curr. Opin. Environ. Sustain. 22, 69-74 (2016). doi:10.1016/J.COSUST.2017.04.006

46. Mock, M. et al. "Something inside me has been set in motion": Exploring the psychological wellbeing of people engaged in sustainability initiatives. Ecol. Econ. 160, 1-11 (2019). doi:10.1016/j.ecolecon.2019.02.002

47. Klar, M. \& Kasser, T. Some Benefits of Being an Activist: Measuring Activism and Its Role in Psychological Well-Being. Polit. Psychol. 30, 755-777 (2009). doi:10.1111/j.14679221.2009.00724.x

48. Mulder, K., Costanza, R. \& Erickson, J. The contribution of built, human, social and natural capital to quality of life in intentional and unintentional communities. Ecol. Econ. 59, 13-23 (2006). doi:10.1016/j.ecolecon.2005.09.021

49. Davidson, S. Global Action Plans's EcoTeams Programme. in Low Carbon Communities Handbook (eds. Peters, M., Fudge, S. \& Jackson, T.) (Edward Elgar Publishing Limited, 2016). Available at: http://www.cagoxfordshire.org.uk/low-carbon-communities-handbook.

50. Olli, E., Grendstad, G. \& Wollebaek, D. Correlates of Environmental Behaviors. Environ. Behav. 
33, 181-208 (2001). doi:10.1177/0013916501332002

51. Andersson, D., Nässén, J., Larsson, J. \& Holmberg, J. Greenhouse gas emissions and subjective well-being: An analysis of Swedish households. Ecol. Econ. 102, 75-82 (2014).

doi:10.1016/j.ecolecon.2014.03.018

52. Ambrey, C. L. \& Daniels, P. Happiness and footprints: assessing the relationship between individual well-being and carbon footprints. Environ. Dev. Sustain. 19, 895-920 (2017). doi:10.1007/s10668-016-9771-1

53. Daly, M. Quantifying the environmental impact of ecovillages and co-housing communities: a systematic literature review. Local Environment 22, 1358-1377 (2017). doi:10.1080/13549839.2017.1348342

54. Howell, R. A. Living with a carbon allowance: The experiences of carbon rationing action groups and implications for policy. Energy Policy 41, 250-258 (2012). doi:10.1016/j.enpol.2011.10.044

55. Grinde, B. et al. Quality of Life in Intentional Communities. Soc. Indic. Res. 137, 625-640 (2018). doi:10.1007/s11205-017-1615-3

56. GLAMURS, Dumitru, A. \& García Mira, R. et al. Green Lifestyles, Alternative Models and Upscaling Regional Sustainability. (2016). Available at: www.glamurs.eu. (Accessed: 12th March 2018)

57. Diekmann, A., Preisendörfer, P. \& Preisendofer, P. Green and Greenback: The behavioral effects of environmental attitudes in low-cost and high-cost situations. Ration. Soc. 15, 441-472 (2003). doi:10.1177/1043463103154002

58. Diener, E., Emmons, R. A., Larsen, R. J. \& Griffin, S. The Satisfaction with Life Scale. J. Pers. Assess. 49, 71-75 (1985). doi:10.1207/s15327752jpa4901_13

59. Minkov, M. Cross-Cultural Analysis. (SAGE, 2013).

60. Tay, L. \& Diener, E. Needs and subjective well-being around the world. J. Pers. Soc. Psychol. 101, 354-65 (2011). doi:10.1037/a0023779

61. Diener, E., Diener, M. \& Diener, C. Factors predicting the subjective well-being of nations. $J$. Pers. Soc. Psychol. 69, 851-864 (1995). doi:10.1037/0022-3514.69.5.851

62. EFSA. The EFSA Comprehensive European Food Consumption Database. (2015). Available at: http://www.efsa.europa.eu/en/food-consumption/comprehensive-database. (Accessed: 18th February 2016)

63. Vásquez, F., Vita, G. \& Müller, D. Food Security for an Aging and Heavier Population. Sustainability 10, 3683 (2018). doi:10.3390/su10103683

64. Wood, R. et al. Global Sustainability Accounting-Developing EXIOBASE for Multi-Regional Footprint Analysis. Sustainability 7, 138-163 (2015). doi:10.3390/su7010138

65. Frischknecht, R. et al. The ecoinvent database: Overview and methodological framework. Int. J. Life Cycle Assess. 10, (2005).

66. Institut Wohnen und Umwelt GmbH. TABULA Calculation Method - Energy Use for Heating and Domestic Hot Water - Reference Calculation and Adaptation to the Typical Level of Measured Consumption. 56 (2013).

67. Zhang, X., Luo, L. \& Skitmore, M. Household carbon emission research: An analytical review of 
measurement, influencing factors and mitigation prospects. J. Clean. Prod. 103, 873-883 (2015). doi:10.1016/j.jclepro.2015.04.024

68. Dubois, G. et al. It starts at home? Climate policies targeting household consumption and behavioral decisions are key to low-carbon futures. Energy Res. Soc. Sci. 52, 144-158 (2019). doi:10.1016/j.erss.2019.02.001

69. Tukker, A., Cohen, M. J., Hubacek, K. \& Mont, O. The impacts of household consumption and options for change. J. Ind. Ecol. 14, 13-30 (2010). doi:10.1111/j.1530-9290.2009.00208.x

70. Wrosch, C. Book Review: Life goals and well-being: Towards a positive psychology of human striving. Int. J. Behav. Dev. 26, 476-478 (2002). doi:10.1177/016502540202600506

71. Vita, G. The Environmental Impacts of Human Needs and Lifestyles: Connecting the global economy, natural resources and human well-being. (Norwegian University of Science and Technology, 2018). doi:http://hdl.handle.net/11250/2578271

72. Hertwich, E. G. \& Peters, G. P. Carbon footprint of nations: A global, trade-linked analysis. Environ. Sci. Technol. 43, 6414-6420 (2009). doi:10.1021/es803496a

73. Wamsler, C. et al. Mindfulness in sustainability science, practice, and teaching. Sustain. Sci. 13, 143-162 (2018). doi:10.1007/s11625-017-0428-2

74. Wilson, J., Tyedmers, P. \& Spinney, J. E. L. An Exploration of the Relationship between Socioeconomic and Well-Being Variables and Household Greenhouse Gas Emissions. J. Ind. Ecol. 17, 880-891 (2013). doi:10.1111/jiec.12057

75. Diener, E., Scollon, C. N. \& Lucas, R. E. The evolving concept of subjective well-being: The multifaceted nature of happiness. in Advances in cell aging and gerontology: Vol. 15 (eds. Costa, P. T. \& Siegler, I. C.) 187-220 (Elsevier, 2004).

76. Kahneman, D. \& Deaton, A. High income improves evaluation of life but not emotional wellbeing. Proc. Natl. Acad. Sci. 107, 16489-16493 (2010). doi:10.1073/pnas.1011492107

77. Lamb, W. F. \& Steinberger, J. K. Human well-being and climate change mitigation. Wiley Interdiscip. Rev. Clim. Chang. 8, 1-16 (2017). doi:10.1002/wcc.485

78. Feola, G. \& Butt, A. The diffusion of grassroots innovations for sustainability in Italy and Great Britain: an exploratory spatial data analysis. Geogr. J. 183, 16-33 (2017). doi:10.1111/geoj.12153

79. Seyfang, G. \& Longhurst, N. What influences the diffusion of grassroots innovations for sustainability? Investigating community currency niches. Technol. Anal. Strateg. Manag. 28, 1-23 (2016). doi:10.1080/09537325.2015.1063603

80. Seyfang, G. \& Haxeltine, A. Growing grassroots innovations: Exploring the role of communitybased initiatives in governing sustainable energy transitions. Environ. Plan. C Gov. Policy 30, 381-400 (2012). doi:10.1068/c10222

81. Smith, A., Fressoli, M. \& Thomas, H. Grassroots innovation movements: challenges and contributions. J. Clean. Prod. (2012). doi:10.1016/j.jclepro.2012.12.025

82. Ockwell, D. \& Whitmarsh, L. Forcing People to be Green or Fostering Grass-Roots Engagement ? Sci. Commun. 30, 305-327 (2015). doi:10.1177/1075547008328969

83. Geels, F. W., Schwanen, T., Sorrell, S., Jenkins, K. \& Sovacool, B. K. Reducing energy demand through low carbon innovation: A sociotechnical transitions perspective and thirteen research debates. Energy Res. Soc. Sci. 40, 23-35 (2018). doi:10.1016/j.erss.2017.11.003 
84. Moore, M.-L., Westley, F. R. \& Nicholls, A. The Social Finance and Social Innovation Nexus. J. Soc. Entrep. 3, 115-132 (2012).

doi:10.1080/19420676.2012.725824org/10.1080/19420676.2012.725824 